www.jmscr.igmpublication.org Impact Factor 5.244

Index Copernicus Value: 83.27

ISSN (e)-2347-176x ISSN (p) 2455-0450

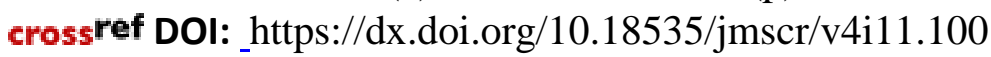

Journal Of Medical Science And Clinical Research

\title{
Evaluation of Serum Autotaxin as a Novel Noninvasive Marker for Assessment of Hepatic Fibrosis in Chronic Hepatitis C Patients
}

\author{
Authors \\ Mahmoud A. Al-Azoony ${ }^{1}$, Jehan H.Sabry ${ }^{2}$, Hisham A. Issa ${ }^{3}$, Maha Z. Omar ${ }^{4}$, \\ Abdelmoneam Ahmed ${ }^{5}$, Doaa M. Abd Almoneim ${ }^{6}$ \\ ${ }^{1,2,3}$ Dept of Clinical and Chemical Pathology, Benha Faculty of Medicine, Benha University, Egypt \\ ${ }^{4}$ Dept of Hepatology, Gastroenterology and Infectious Diseases, Benha Faculty of Medicine, Benha \\ University, Egypt \\ ${ }^{5}$ Department of Internal Medicine, Benha Faculty of Medicine, Benha University, Egypt \\ ${ }^{6}$ Department of Clinical Pathology, Benha Health Insurance Hospital, Egypt
}

\begin{abstract}
Egypt has a high prevalence of HCV infection which causes hepatic fibrosis. Assessment of the degree of hepatic fibrosis is essential for decision of antiviral therapy. Untill now, liver biopsy is the gold standard for assessment of hepatic fibrosis but it is an invasive procedure. The aim of this study was to assess the utility of serum autotaxin level as a marker of liver fibrosis in chronic hepatitis $C$ patients in comparison with liver biopsy.Sixty HCV patients with hepatic fibrosis confirmed with liver biopsy and 20 healthy subjects were inrolled in the current study.Lab assessment included CBC, fasting serum glucose, liver and kidney function tests, serum AFP, hepatitis markers (HCVAb, HBsAg), PCR for HCV RNA and serum autotaxin (using sandwich ELISA).Results revealed that serum ATX levels were significantly increased in HCV group versus control group and were positively correlated with the stage of fibrosis. Serum autotaxin level at cutoff value $(<115.8 \mathrm{ng} / \mathrm{ml})$ was the best parameter in detection of F0 with AUC $(0.79)$, at a cutoff value $(\geq 180.3 \mathrm{ng} / \mathrm{ml})$ was the best parameter in detection of advanced fibrosis $(\geq F 3)$ with AUC (0.82) and at a cutoff value $(\geq 189.2 \mathrm{ng} / \mathrm{ml})$ was the best parameter in detection of F4 with AUC (0.85).

It was concluded that serum autotaxin level is a valuable test for exclusion of fibrosis and detection of advanced fibrosis and cirrhosis but lacks discrimination of intermediate fibrosis stages.
\end{abstract}

Keywords: Hepatitis $C$, autotaxin, hepatic fibrosis.

\section{Introduction}

Hepatitis $\mathrm{C}$ is a major health problem. Chronic hepatitis $\mathrm{C}$ is a slowly progressive inflammatory disease which can lead to cirrhosis with all its complications ${ }^{[1]}$. In Egypt, the prevalence rate reaches $15 \%$ in rural areas, with some age groups suffering from prevalence rates up to $50 \%$. $13.6 \%$ of volunteer blood donors have anti-HCV antibodies, this high seropositive rate among Egyptians is about 35 folds higher than other countries ${ }^{[2]}$.
Liver fibrosis is the excessive accumulation of extracellular matrix proteins including collagen that results from chronic damage to the liver ${ }^{[3]}$. The assessment of the stage of liver fibrosis is essential for prognosis and for deciding on antiviral treatment ${ }^{[4]}$.

Liver biopsy is recommended as the gold standard method for determining fibrosis stage, prognosis and therapeutic indications in patients with chronic liver disease. However, liver biopsy is an invasive procedure and is associated with 
many complications ${ }^{[1]}$. Approximately 1-3\% of patients require hospitalization for complications, and a quarter of them report pain after percutaneous liver biopsy. The diagnostic accuracy of liver biopsy for assessment of hepatic fibrosis is influenced by the quality of the biopsy samples. In addition, there are many absolute or relative contraindications to liver biopsy, including severe coagulopathy ${ }^{[5]}$. Hence, several noninvasive tests have been proposed in an attempt to predict the degree of fibrosis and replace liver biopsy ${ }^{[6]}$.

Autotaxin (ATX), is a secreted glycoprotein that belongs to the ectonucleotidepyrophosphatase/ phosphodiesterase (NPP) family ${ }^{[7]}$. ATX hydrolyzes lysophosphatidylcholine to produce lysophosphtidic acid, a multifunctional bioactive lipid mediator ${ }^{[8]}$. ATX is a vital enzyme which is needed for early embryological development ${ }^{[9]}$. Physiologically, the most important role of ATX after birth is probably in wound healing and tissue remodeling. LPA is a potent activator of platelet aggregation and it also stimulates the growth and migration of fibroblasts, vascular smooth muscle cells, endothelial cells and keratinocytes ${ }^{[10]}$. Lysophosphatidic acid (LPA) activates hepatic stellate cells (HSC) which are the main cell type involved in development of liver fibrosis, stimulates their contraction and inhibits their $\operatorname{apoptosis}^{[11]}$.

Elevated serum ATX levels are an indicator for activation of HSC during development of fibrosis and cirrhosis ${ }^{[12]}$. As ATX is cleared by sinusoidal endothelial cells, dysfunctional endothelium may be a cause for higher blood concentrations of ATX in cirrhotic patients ${ }^{[13]}$. Recently, a connection between liver fibrosis and serum or plasma LPA and ATX emerged in patients with chronic HCV infection ${ }^{[14]}$. However, serum ATX in different stages of liver cirrhosis and its prognostic value has not yet been investigated ${ }^{[15]}$. We aimed in this study to investigate the utility of serum autotaxin level as a noninvasive marker of hepatic fibrosis and if serum ATX can be an indicator for the degree of liver fibrosis compared to liver biopsy in chronic HCV patients.

\section{Subjects and methods}

Study population

The current case control study was carried out on 80 subjects. All included candidates were chosen from attendants to the Department of Hepatology, Gastroenterology and Infectious Diseases in Benha University Hospital during the period from July 2014 to July 2015. All included candidates gave a written informed consent for using their serum samples. They were categorized into 2 groups.

Group1 (patients' group): included 60chronic hepatitis C patients, 39 males (65\%) and 21 females (35\%).Chronic HCV diagnosis was based on elevated serum transaminase levels for at least six months and positive $\mathrm{HCV}$ antibody by enzyme-linked immunosorbent assay and confirmed by quantitative detection of circulating HCV RNA using polymerase chain reaction (PCR). Liver biopsywas taken from every patient for staging of fibrosis. Patients were subgrouped into five subgroups according to stage of liver fibrosis (from F0 to F4).Inclusion criteria were: age > 18 years old and positive HCV Abs confirmed by HCV RNA detection by PCR. Exclusion criteria were: age $<18$ years old, HBV infected patients, patients with hepatocellular carcinoma (HCC) and other causes of liver disease e.g alcoholism and autoimmune hepatitis. Group 2 (control group): included 20 healthy subjects (free from liver diseases), they were 10 males $(50 \%)$ and 10 females $(50 \%)$.

\section{Ethical consideration}

The study protocol was approved by the ethical committee of Benha faculty of medicine and its university hospital.

\section{Spicemen collection}

Blood samples were collected by peripheral venipuncture under complete aseptic precautions. Then each sample was divided into 3 parts: (1.8) $\mathrm{ml}$ blood for each $0.2 \mathrm{ml} \mathrm{Na}$ citrate for measurement of PT and international normalized ratio, $2 \mathrm{ml}$ on EDTA for complete blood count and the rest of the sample was used for separation 
of serum. Serum was separated by allowing samples to clot for 30 minutes at room temperature, then the tube was centrifuged for 15 minutes at 1500 r.p.m. then the sera were divided into aliquots.

\section{Lab investigations}

Fasting serum glucose, liver function tests (AST, ALT, ALP, total bilirubin, direct bilirubin, serum albumin), kidney function tests (serum creatinine and urea) were performed using Biosystem A15 auto-analyzer.

Serum AFP was measured using CanAg AFP EIA kit provided by (FUJIREBIO Diagnostic, Inc., SE-402 42 Geteborg, Sweden) ${ }^{[16]}$.

Serum autotaxin was measured using Quantikine Human ENPP-2/Autotaxin ELISA kit (manufactured and distributed by R\&D systems, inc. USA \& Canada) according to the recommendations of the manufacturer.

Autotaxin assay is a sandwich ELISA in which a monoclonal antibody specific for ENPP-2 has been pre-coated onto a microplate. Then, Standards and samples are pipetted into the wells, then washed. An enzyme-linked polyclonal antibody specific for ENPP-2 is added to the wells. After washing, a substrate solution is added to the wells and color develops. The color development is stopped and the intensity of the color is measured ${ }^{[17]}$.

All laboratory investigations were done in the department of Clinical and Chemical Pathology, Benha University hospital.

\section{Calculation of laboratory scores}

APRI (Aspartate/platelet ratio index) was calculated according to the formula:

- $\mathrm{APRI}=\left[(\mathrm{AST} / \mathrm{ULN}) / \mathrm{PLT}\left(\times 10^{9} / \mathrm{L}\right)\right] \times 100$ (Wai et al ${ }^{[18]}$ ).

- API (Age platelet index)was calculated according to the formula:

Age score + platelet count score

Age: $<30=5 ; 30-39=1 ; 40-49=2 ; 50-59=3 ; 60$ $69=4 ; \geq 70=5$.

Platelet count $\left(\times 10^{9} / \mathrm{L}\right): \geq 225=0 ; 200-224=1$; $175-199=2 ; 150-174=3 ; 125-149=4 ;<125=5$ (Poynard and Bedossa $^{[19]}$ ).
Histopathological Assessment of liver biopsies:

All biopsies were obtained by trucut needle (biopsy gun, G16) with a core length of at least 1 $\mathrm{cm}$ including a minimum of 6 portal tracts. All were stained by haematoxylin-eosin (H \& E)as well as Masson Trichrome stains. The METAVIR scoring system according to Bedossa and Poynard [20] was applied by the same experienced hitopathologist. Histological staging based on degree of fibrosis has 5 stages $(\mathrm{F} 0-\mathrm{F} 4)$ as following (F0: No fibrosis; F1: portal fibrosis without septa; F2 : portal fibrosis with rare septa. F3 : portal fibrosis with numerous septa without cirrhosis; F4 : cirrhosis).

\section{Statistical Analysis}

The collected data were tabulated and analyzed using SPSS version 16 software (SpssInc, Chicago, ILL Company). Categorical data were presented as number and percentages while quantitative data were expressed as mean and standard deviation or median and Inter Quartilerange (IQR). Chi square test $\left(\mathrm{X}^{2}\right)$, Fisher's test, Spearman's correlation coefficient (rho), St."t", Man Whitney U test and Krauskal Wallis test were the used tests of significance. ROC curve was used to determine cutoff values with optimum sensitivity and specificity of the studied markers in detection of different stages of fibrosis.

\section{Results}

This study is a case control study that included 60 hepatitis $\mathrm{C}$ patients with hepatic fibrosis proved with liver biopsy, their ages ranged from 21 - 58 years with mean of 43.98years and 20 healthy subjects (free from liver diseases) as control group their ages ranged from 24 - 62 years with mean of 41.95years. Patients were divided into five groups according to METAVIR scoring system (from F0 to F4). They were 6 patients in F0, 15 patients in $\mathrm{F} 1,18$ patients in $\mathrm{F} 2,14$ patients in $\mathrm{F} 3,7$ patients in F4.

Lab investigations in the form of CBC, PT, INR, fasting serum glucose, liver function tests (AST, ALT, ALP, total bilirubin, direct bilirubin, serum albumin), kidney function tests (serum creatinine 
and urea) were recorded in table (1) where all data were expressed as mean \pm SD while serum AFP, serum ATX, APRI, API were expressed as median and IQR.

The current study revealed that there was high statistically significant increase in serum autotoxin in patients' group (median=162.9) versus control group (median=36.8) (P value <0.001) (table 1).While there was no significant difference between males and females as regarding the mean values of serum autotaxin level $(\mathrm{P}$ values were 0.75 for patients' group and 0.14 for control group (table 2).

High statistically significant increase in PT and statistically significant increase in INR, ALT, AFP, APRI, API were found in patients' group versus control group (table 1).

The stage of fibrosis showed highly significant positive correlations with AST, AFP, serum autotaxin ( $\mathrm{P}$ value <0.001), APRI ( $\mathrm{P}$ value $<0.001$ ), and API (P value 0.001) scores (figure 1 $\mathrm{a}, \mathrm{b}, \mathrm{c})$, significant positive correlations with age , PT , INR, serum direct bilirubin, ALT , ALP ( P values were $0.008,0.042,0.016,0.047,0.043$, 0.012 respectively) and significant negative correlations with platelets and serum albumin ( $\mathrm{P}$ values were $0.025,0.007$ respectively). While it showed no correlation with $\mathrm{Hb}$, WBCs, fasting serum glucose, total bilirubin, urea, creatinine and PCR results.

Also in the current study, serum autotaxin level showed a significant positive correlation with age, fasting serum glucose, ALP, urea, API, AST (figure $2 \mathrm{a}, \mathrm{b}$ ) (P values were 0.012, 0.025, 0.002, $0.005,0.014,0.008$ respectively) and highly significant positive correlation with AFP (P value $<0.001)$.

Serum autotaxin level at cutoff value $(<115.8$ $\mathrm{ng} / \mathrm{ml}$ ) was the best parameter in detection of F0 with AUC (0.79), sensitivity (83.3\%), specificity $(74.1 \%)$ and accuracy $(79.2 \%)(\mathrm{P}$ value $=0.02)$ (table3, figure 3).

Serum autotaxin at cutoff value $(<150.4 \mathrm{ng} / \mathrm{ml})$ had AUC (0.64), sensitivity (73.3\%), specificity $(60 \%)$ and accuracy $(64.1 \%)(\mathrm{P}$ value $=0.1)$ in detection of F1.Serum autotaxin at cutoff value $(<162.9 \mathrm{ng} / \mathrm{ml})$ had AUC (0.58), sensitivity (61.1\%), specificity (54.8\%) and accuracy $(57.5 \%)$ (P value $=0.35)$ in detection of $\mathrm{F} 2$.

APRI at cutoff value $(\geq 0.444)$ was the best parameter in detection of significant fibrosis $(\geq$ F2) with AUC (0.75), sensitivity (74.4\%), specificity (85.7\%) and accuracy (75.4\%) (P value $=0.001)$ followed by Serum autotaxin whose cutoff value $(\geq 124.7 \mathrm{ng} / \mathrm{ml})$ had $\mathrm{AUC}=0.75$, sensitivity (79.5\%), specificity (71.4\%) and accuracy $(75 \%)(\mathrm{P}$ value $=0.002)$ in detection of significant fibrosis ( $\geq$ F2).

API at cutoff value $(\geq 3.5)$ was the best parameter in detection of F3 with AUC (0.73), sensitivity (64.3\%), specificity (67.4\%) and accuracy $(73.4 \%)$ ( $\mathrm{P}$ value $=0.008)$ while serum autotaxin level at cutoff value $(\geq 162.9 \mathrm{ng} / \mathrm{ml})$ had AUC (0.71), sensitivity (78.6\%), specificity (58.7\%) and accuracy $(71.4 \%)$ in detection of F3(P value=0.016).

Serum autotaxin level at cutoff value $(\geq 180.3$ $\mathrm{ng} / \mathrm{ml}$ ) was the best parameter in detection of advanced fibrosis ( $\geq$ F3)with AUC (0.82), sensitivity (71.4\%), specificity (84.6\%) and accuracy $(82.2 \%)(\mathrm{P}$ value $=<0.001)$ followed by APRI score(table 4, figure 4).

Serum autotaxin level at cutoff value $(\geq 189.2$ $\mathrm{ng} / \mathrm{ml}$ ) was the best parameter in detection of F4 with AUC (0.85), sensitivity (85.7\%), specificity $(71.7 \%)$ and accuracy $(84.6 \%)(\mathrm{P}$ value $=0.003)$ followed by APRI score (table 5, figure 5). 
Table (1): Comparing the studied groups as regarding age, sex and laboratory investigation:

\begin{tabular}{|l|c|c|c|c|c|}
\hline \multirow{2}{*}{ Variable } & \multicolumn{2}{|c|}{$\begin{array}{c}\text { HCV group } \\
\text { (N=60) }\end{array}$} & \multicolumn{2}{c|}{$\begin{array}{c}\text { Controls } \\
(\mathrm{N}=20)\end{array}$} & \multirow{2}{*}{ P value } \\
\cline { 2 - 5 } & Mean & \pm SD & Mean & \pm SD & \\
\hline Age (years) & 43.98 & 9.81 & 41.95 & 9.96 & 0.42 \\
\hline Hb (gm/dl) & 13.56 & 1.794 & 14.28 & 1.355 & 0.1 \\
\hline RBCs & 4.88 & 0.779 & 4.92 & 0.815 & 0.85 \\
\hline WBCs & 6.20 & 2.029 & 5.37 & 0.715 & 0.08 \\
\hline PLTs & 229.56 & 76.153 & 235.95 & 48.427 & 0.72 \\
\hline MPV & 8.42 & 1.145 & 8.98 & 1.290 & 0.07 \\
\hline Fasting serum glucose (mg/dl) & 101.96 & 29.215 & 96.65 & 15.725 & 0.44 \\
\hline Albumin (gm/dl) & 4.11 & 0.56082 & 4.13 & 0.24979 & 0.61 \\
\hline PT (seconds) & 14.56 & 1.76415 & 13.05 & 0.08272 & $<0.001^{*}$ \\
\hline INR & 1.12 & 0.13689 & 1.03 & 0.06231 & $0.001^{*}$ \\
\hline T. bilirubin (mg/dl) & 0.83 & 0.33828 & 0.75 & 0.18423 & 0.75 \\
\hline D. bilirubin (mg/dl) & 0.28 & 0.14238 & 0.25 & 0.04767 & 0.73 \\
\hline AST(U/L) & 44.63 & 25.59990 & 33.40 & 4.51197 & 0.16 \\
\hline ALT (U/L) & 47.41 & 35.76064 & 30.60 & 6.12501 & $0.033^{*}$ \\
\hline ALP (U/L) & 106.55 & 57.59779 & 80.90 & 11.21512 & 0.07 \\
\hline Urea (mg/dl) & 30.25 & 6.00016 & 30.55 & 4.63936 & 0.82 \\
\hline Creatinine (mg/dl) & 0.93 & 0.20839 & 0.92 & 0.11118 & 0.65 \\
\hline & Median & IQR & Median & IQR & \\
\hline AFP(ng/ml) & 4.2 & $2.69-8.97$ & 3.4 & $2.55-4.0$ & $0.032^{*}$ \\
\hline Serum autotaxin (ng/ml) & 162.9 & $96.2-261$ & 36.8 & $29.2-45.7$ & $<0.001^{*}$ \\
\hline APRI & 0.49 & $0.28-0.84$ & 0.35 & $0.28-0.43$ & $0.017^{*}$ \\
\hline API & 3.0 & $2.0-5.0$ & 2.0 & $1.0-3.75$ & $0.02^{*}$ \\
\hline
\end{tabular}

Table (2) comparing males and females as regarding mean values of serum Autotaxin level in the studied groups:

\begin{tabular}{|c|c|c|c|c|c|}
\hline \multirow[t]{2}{*}{ Variable } & \multicolumn{2}{|c|}{$\begin{array}{c}\text { HCV group } \\
(\mathrm{N}=60)\end{array}$} & \multicolumn{2}{|c|}{$\begin{array}{c}\text { Controls } \\
(\mathrm{N}=20)\end{array}$} & \multirow[t]{2}{*}{ Test of sig. } \\
\hline & Mean & $\pm \mathrm{SD}$ & Mean & $\pm \mathrm{SD}$ & \\
\hline \multirow{4}{*}{$\begin{aligned} \text { S. Autotaxin }(\mathrm{ng} / \mathrm{ml}) & \\
& \text { female } \\
& \text { male }\end{aligned}$} & & & & & \multirow[t]{4}{*}{ St. "t"=0.8 } \\
\hline & 179.09 & 87.41210 & 40.7 & 8.25 & \\
\hline & 188.23 & 135.22116 & 33.3 & 12.56 & \\
\hline & \multicolumn{2}{|c|}{$\mathrm{P}$ value $=0.75$} & \multicolumn{2}{|c|}{$\mathrm{P}$ value $=0.14$} & \\
\hline
\end{tabular}

(a)

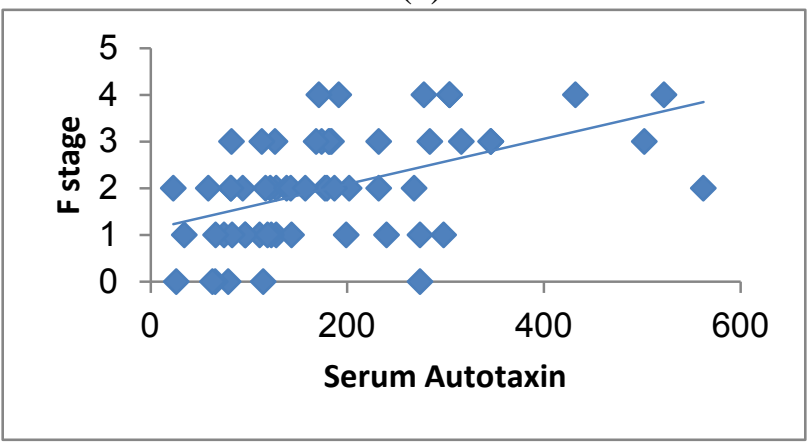

(b)

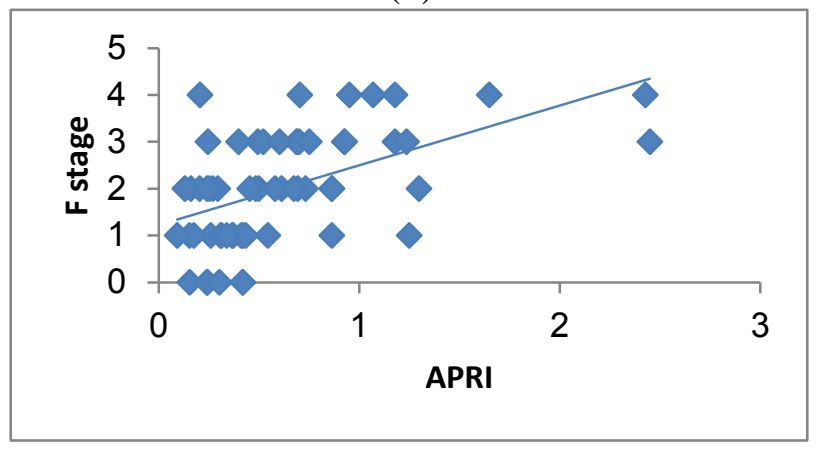


(c)

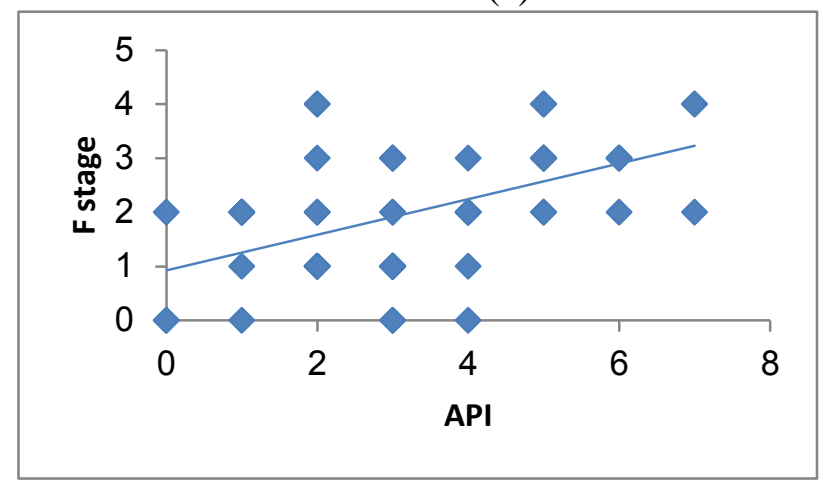

Figure (1): Spearman's correlation between the fibrosis stage and the three noninvasive markers: (a)Spearman's correlation between serum autotaxin $(\mathrm{ng} / \mathrm{ml})$ and the fibrosis stage.(b) Spearman's correlation between APRI and the fibrosis stage. (c)Spearman's correlation between API and the fibrosis stage.

(a)

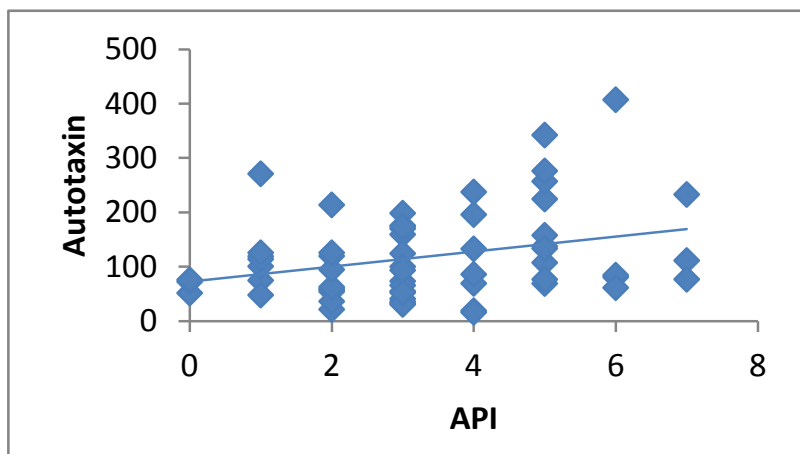

(b)

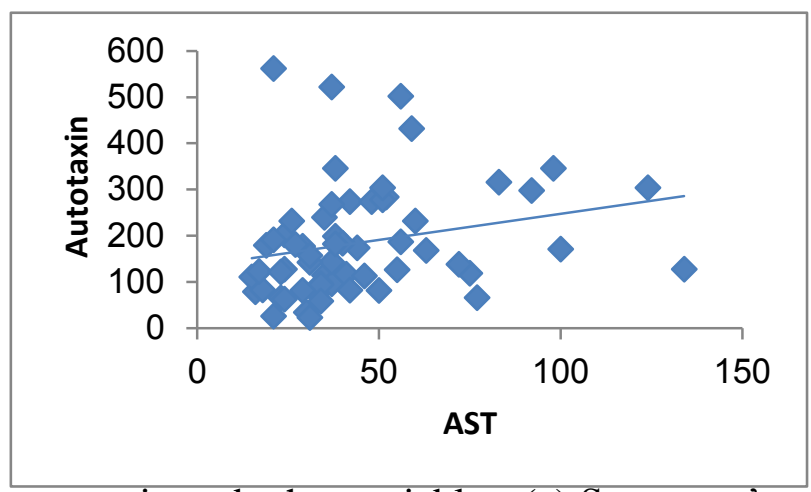

Figure (2): Spearman's correlation between serum autotoxin and other variables: (a) Spearman's correlation between serum autotaxin ( $\mathrm{ng} / \mathrm{ml}$ )and API.(b)Spearman's correlation between serum autotaxin (ng/ml)and AST (U/L).

Table (3) Performance of the autotaxin, APRI and API in detection of F0:

\begin{tabular}{|l|c|c|c|c|c|c|c|c|c|}
\hline Marker & $\begin{array}{c}\text { Cutoff } \\
\text { Value }\end{array}$ & Sens\% & Spec\% & PPV\% & NPV\% & Accuracy \% & AUC & $95 \%$ CI & P \\
\hline $\begin{array}{l}\text { S. autotaxin } \\
(\mathrm{ng} / \mathrm{ml})\end{array}$ & $<115.8$ & $83.3 \%$ & $74.1 \%$ & $26.3 \%$ & $97.6 \%$ & $79.2 \%$ & 0.79 & $0.57-1.0$ & $0.02 *$ \\
\hline APRI & $<0.42$ & $100 \%$ & $63 \%$ & $23.1 \%$ & $100 \%$ & $78.1 \%$ & 0.78 & $0.65-0.91$ & $0.025 *$ \\
\hline API & $<2.5$ & $83.3 \%$ & $42.6 \%$ & $13.9 \%$ & $95.8 \%$ & $73.1 \%$ & 0.73 & $0.52-0.94$ & 0.065 \\
\hline
\end{tabular}

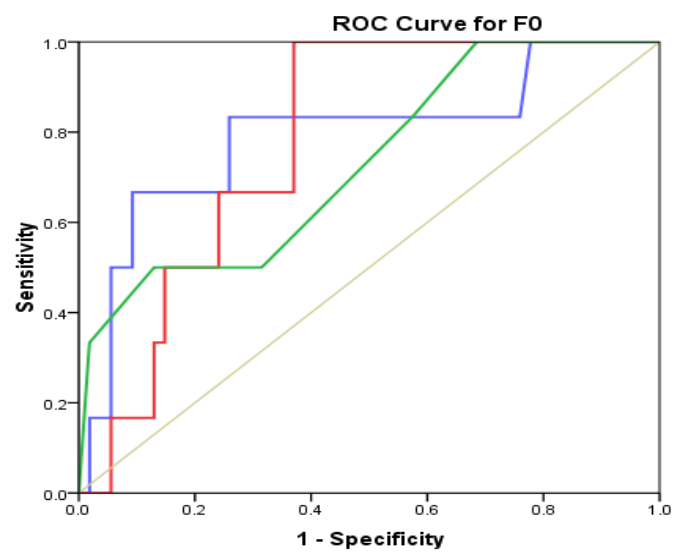

Source of the Curve - $\mathrm{S}$. Autotaxin - APRI Reference Line

Figure (3): ROC curve of performance of the autotaxin, APRI and API in detection of F0. 


\section{JMSCR Vol||04||Issue||11||Page 14128-14139||November}

Table (4) Performance of the autotaxin, ferretin, APRI and API in detection of advanced fibrosis ( $\geq$ F3):

\begin{tabular}{|l|l|l|l|l|l|l|l|l|l|}
\hline Marker & $\begin{array}{l}\text { Cutoff } \\
\text { Value }\end{array}$ & Sens\% & Spec\% & PPV\% & NPV\% & $\begin{array}{l}\text { Accuracy } \\
\%\end{array}$ & AUC & $95 \%$ CI & P \\
\hline S. autotaxin $(\mathrm{ng} / \mathrm{ml})$ & $\geq 180.3$ & $71.4 \%$ & $84.6 \%$ & $71.4 \%$ & $84.6 \%$ & $82.2 \%$ & 0.82 & $0.71-0.94$ & $<0.001 *$ \\
\hline APRI & $\geq 0.681$ & $71.4 \%$ & $82.1 \%$ & $68.2 \%$ & $84.2 \%$ & $80.8 \%$ & 0.81 & $0.69-0.93$ & $<0.001 *$ \\
\hline API & $\geq 3.5$ & $66.7 \%$ & $74.4 \%$ & $58.3 \%$ & $80.6 \%$ & $78.4 \%$ & 0.78 & $0.66-0.91$ & $<0.001 *$ \\
\hline
\end{tabular}

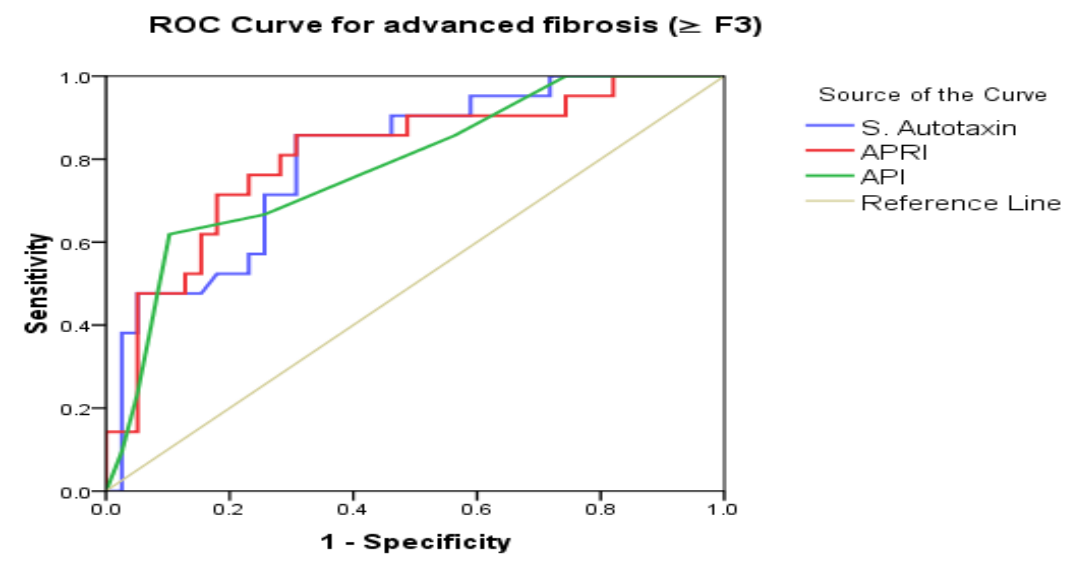

Figure (4): ROC curve of Performance of the autotaxin, APRI and API in detection of advanced fibrosis $(\geq$ F3).

Table (5): Performance of the autotaxin, APRI and API in detection of F4 of cirrhosis:

\begin{tabular}{|l|c|c|c|c|c|c|c|c|c|}
\hline Marker & $\begin{array}{c}\text { Cutoff } \\
\text { Value }\end{array}$ & Sens\% & Spec\% & PPV\% & NPV\% & Accur-acy\% & AUC & 95\%CI & P \\
\hline S. autotaxin (ng/ml) & $\geq 189.2$ & $85.7 \%$ & $71.7 \%$ & $28.6 \%$ & $97.4 \%$ & $84.6 \%$ & 0.85 & $0.73-0.97$ & $0.003 *$ \\
\hline APRI & $\geq 0.703$ & $85.7 \%$ & $77.4 \%$ & $33.3 \%$ & $97.6 \%$ & $79.9 \%$ & 0.8 & $0.58-1.0$ & $0.011 *$ \\
\hline API & $\geq 4.5$ & $71.4 \%$ & $77.4 \%$ & $29.4 \%$ & $95.3 \%$ & $71.8 \%$ & 0.72 & $0.49-0.95$ & 0.062 \\
\hline
\end{tabular}

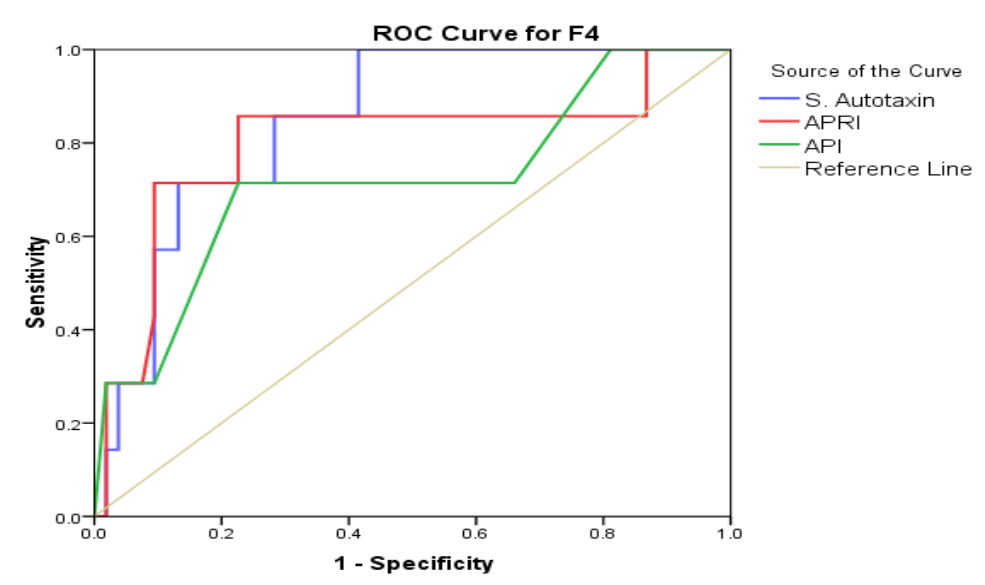

Figure (5): ROC curve of Performance of the autotaxin, APRI and API in detection of F4.

\section{Discussion}

Autotaxin (ATX), or ecto-nucleotide pyrophosphatase/phosphodiesterase-2, is a secreted lysophospholipase D (lysoPLD) that hydrolyzes extracellular lysophospholipids to produce the lipid mediator lysophosphatidic acid
(LPA). ATX-LPA signaling is essential for development and has been implicated in a great diversity of (patho) physiological processes, ranging from lymphocyte homing to tumor progression [21]. Lysophosphatidic acid (LPA) activates hepatic stellate cells (HSC) which are the 
main cell type involved in development of liver fibrosis, stimulates their contraction and inhibits their apoptosis ${ }^{[11]}$.

In the present study we found that serum ATX levels were significantly increased in HCV group versus control group. This camein agreement with many studies ${ }^{[14,15,22,23]}$. Recent evidence indicates that ATX is rapidly cleared from the circulation by liver sinusoidal endothelial cells ${ }^{[13]}$.

HSC are an important factor in the development of liver fibrosis and cirrhosis. On repeated or persistent liver damage they transdifferentiate into myofibroblasts ${ }^{[24]}$. Progression of hepatic fibrosis is associated with an increased number of HSC [25]. Therefore, one can speculate that elevated serum ATX levels are an indicator for activation of HSC during development of fibrosis and cirrhosis ${ }^{[26]}$.

Portal hypertension is a result of enhanced intrahepatic vascular resistance with activation of HSC and endothelial dysfunction as well as splanchnic vasodilatation ${ }^{[27]}$. As ATX is cleared by sinusoidal endothelial cells, dysfunctional endothelium may be a factor for higher blood concentrations of ATX in cirrhotic subjects ${ }^{[13]}$. In contrast to our results, Ezzat et al ${ }^{[28]}$ reported that serum Autotaxin was not a diagnostic marker of liver fibrosis.

In agreement with the results of Ezzat et al ${ }^{[28]}$, this study showed that there was no significant difference between males and females as regarding the mean values of serum autotaxin level. On the contrary, Nakagawa and his colleagues ${ }^{[23]}$ talked about gender bias of ATX expression but they did not give explanation about this bias.

Correlation study between the fibrotic stage and the three noninvasive markers revealed highly significant positive correlations between the fibrosis stage and serum autotaxin, APRI and API scores. This coincided with Fouad et al ${ }^{[29]}$ who found a significant correlation between both APRI and API scores not only with the stage of hepatic fibrosis but also with the grade of activity. Also, many other studies ${ }^{[14,15,22,23]}$ reported a significant positive correlation between serum ATX and the fibrosis stage.

Also, we found a significant negative correlation between platelets and fibrosis stage. This result agreed with Attallah et al ${ }^{[30]}$ who reported that platelet count was correlated with progression of fibrosis. Thrombocytopenia in patients with advanced hepatic fibrosis may be explained by reduction of thrombopoietin synthesis by liver, also portal hypertension leads to pooling of platelets in the enlarged spleen ${ }^{[31]}$.

In the present study there was highly significant positive correlation between AST and fibrosis stage. Also, there was significant positive correlation between ALT and fibrosis stge. These results met the findings of Wai et al ${ }^{[18]}$ who found gradual increase in serum AST level with progression of fibrosis and explained this by the fact that progression of liver fibrosis may reduce the clearance of AST leading to increased serum AST levels. In addition, advanced liver disease may be associated with mitochondrial injury, resulting in increased release of AST which is present in mitochondria and cytoplasm.

Other correlations between the fibrotic stage and the rest of the studied parameters revealed that there was significant positive correlation between PT, INR and fibrosis stage. This came in agreement with Cadranel and Philippe[32] who found that PT was an accurate, cheap and reproducible serum marker for extensive fibrosis, and they advised all clinicians to consider that PT as a reliable marker of fibrosis progression. This is attributed to decreased synthesis of coagulation factors by the liver ${ }^{[33]}$. On the other hand, Coverdale et al ${ }^{[34]}$ reported that PT failed to correlate with fibrosis progression.

We found asignificant negative correlation between serum albumin and fibrosis stage. Friedman et al [35] also reported that hypoalbuminemia was common in chronic liver diseases that could be explained as albumin is the most important plasma protein synthesized by the liver and its synthesis is decreased in advanced hepatic fibrosis. 
Data obtained from this study revealed a significant positive correlation between direct biliubin and fibrosis stage. Hepatocyte damage as in hepatitis $\mathrm{C}$ infection results in reduced efficiency of bilirubin excretion into bile. Conjugated bilirubin refluxes into the circulation and is found in urine ${ }^{[36]}$.

In accordance with Omran et al ${ }^{[37]}$, we observed a highly significant correlation between $\alpha$ fetoprotein and fibrosis stage. Some hypotheses attribute the high AFP level in hepatic damage to the selective transcriptional activation of AFP gene ${ }^{[38]}$.

In the current study there was no significant correlation between PCR results and fibrosis stage. These results coincided with Ibrahim and Mandour ${ }^{[2]}$ finding no significant correlation between HCV RNA titers and the stage of liver fibrosis. On the contrary, Adinolfi and his colleagues ${ }^{[39]}$ concluded in their study that serum HCV-RNA titer correlated with the severity of liver damage, which can be accelerated by high $\mathrm{HCV}$ load. Many factors may cause the discrepancies between these studies. For example, serum HCV load fluctuates, so it is unstable parameter and cannot reflect the degree of liver damage in a given subject ${ }^{[40]}$. Also, HCV replicates in extra-hepatic sites as well as within the liver ${ }^{[41]}$.

In consistency with Shahid et al ${ }^{[42]}$ ALP levels correlated positively with the stage of liver fibrosis. On the other hand, Ibrahim and Mandour ${ }^{\text {[2] }}$ reported that ALP levels were not correlated with fibrosis stage.

On evaluating the performance of the three noninvasive markers (serum autotaxin, APRI and API) in prediction of the degree of liver fibrosis, the results revealed that serum autotaxin level was the best parameter among the three noninvasive parameters in exclusion of fibrosis with AUC (0.79).

All studied markers were considered fair tests in detection of $\mathrm{F} 1$ and $\mathrm{F} 2$.

APRI was the best parameter in detection of significant fibrosis ( $\geq$ F2) with AUC (0.754) followed by serum autotaxin with AUC (0.751).
This came in agreement with Wai et al ${ }^{[18]}$ who found that APRI was a good test in prediction of significant fibrosis $(F \geq 2)$ at cutoff value $>1.5$ the AUC was 0.88. Also, Nakagawa et al ${ }^{[23]}$ found that serum autotaxin level was the second best parameter in both males and females for prediction of significant fibrosis and had sensitivity (70\%), specificity (73.1\%), AUC $(0.799)$ in male and sensitivity $(86.5 \%)$, specificity $(70.6 \%)$, AUC (0.876) in female.

In the current study serum autotaxin level at a cutoff value $(\geq 180.3 \mathrm{ng} / \mathrm{ml})$ was the best parameter in detection of advanced fibrosis $(\geq F 3)$ with AUC (0.82) and at a cutoff value $(\geq 189.2$ $\mathrm{ng} / \mathrm{ml}$ ) was the best parameter in detection of cirrhosis with AUC (0.85). These results came in accordance with Nakagawa and his colleagues ${ }^{\text {[23] }}$ who assessed the performance of serum autotaxin level in prediction of liver fibrosis in comparison with serum hyaluronic acid level and APRI and found that serum autotaxinwas the best parameter in male with sensitivity (82.4\%), specificity (74.4\%), AUC (0.863) and the third-best parameter in female with sensitivity $(81.5 \%)$, specificity (77.3\%), AUC (0.872) for prediction of cirrhosis.

\section{In Conclusion}

Serum autotaxin level is a valuable test for exclusion of fibrosis and detection of advanced fibrosis and cirrhosis in chronic HCV patients. As it lacks discrimination of intermediate stages of fibrosis, liver biopsy until now remains the gold standard method for discrimination of different stages of hepatic fibrosis. Further extended studies should be done on larger numbers of chronic hepatitis $\mathrm{C}$ patients using various combinations of non invasive fibrosis markers to detect the excellent test that can replace liver biopsy.

\section{References}

1. Palmeri ML, Wang MH, Rouze NC, Abdelmalek MF, Guy CD, Moser B, Diehl AM, et al. Noninvasive evaluation of hepatic fibrosis using acoustic radiation force-based shear 
stiffness in patients with nonalcoholic fatty liver disease. Journal of Hepatology 2011; 55(3): 666-672.

2. Ibrahim WS and Mandour EM. Correlation of Liver Biopsy with Liver Enzymes and PCR among Egyptian Patients with Chronic Hepatitis C. Academic Journal of Cancer Research 2014; 7 (2): 59-64.

3. Friedman SL. Liver fibrosis from bench to bedside. J Hepatol2003; 38(1): 38-53.

4. Lauer GM and Walker BD. Hepatitis C virus infection. $N$ Engl J Med 2001; 345(1): 41-52.

5. Boursier J, Isselin G, Fouchard-Hubert I, Oberti F, Dib N, Lebigot J, Bertrais S, et al. Acoustic radiation force impulse: a new ultrasonographic technology for the widespread noninvasive diagnosis of liver fibrosis. European journal of gastroenterology \&hepatology 2010; 22(9):1074-84.

6. Leroy V, Hilleret MN, Sturm N, Trocme C, Renversez JC, Faure P, Morel F, et al. Prospective comparison of six noninvasive scores for the diagnosis of liver fibrosis in chronic hepatitis C. J Hepatol 2007; 46(5): 775-782.

7. Nakanaga K, Hama $K$ and Aoki J. Autotaxin--an LPA producing enzyme with diverse functions. Journal of biochemistry 2010; 148(1):13-24.

8. Ikeda $\mathrm{H}$ and Yatomi $\mathrm{Y}$. Autotaxin in liver fibrosis.ClinChimActa 2012; 413(23-1

9. Koike S, Yutoh Y, Keino-Masu K, Noji S, Masu $M$ and Ohuchi H.Autotaxin is required for the cranial neural tube closure and establishment of the midbrainhindbrain boundary during mouse development. DevDyn 2011; 240(2): 413421.

10. Brindley DN. Lipid phosphate phosphatases and related proteins: signaling functions in development, cell division, and cancer. $J$ Cell Biochem 2004; 92(5):900-912.
11. Ikeda $H$, Nagashima $K$, Yanase $M$, Tomiya T, Arai M, Inoue Y, Tejima K, et al. Involvement of Rho/Rho kinase pathway in regulation of apoptosis in rat hepatic stellate cells. Am J Physiol Gastrointest Liver Physiol 2003; 285(5): 880-886.

12. Tanaka M, Okudaira S, Kishi Y, Ohkawa R, Iseki S, Ota M, Noji S, Yatomi Y, Aoki J, Arai H. Autotaxin stabilizes blood vessels and is required for embryonic vasculature by producing lysophosphatidic acid. J BiolChem 2006; 281(35): 2582225830.

13. Jansen S, Andries M, Vekemans K, Vanbilloen H, Verbruggen A, Bollen M.Rapid clearance of the circulating metastatic factor autotaxin by the scavenger receptors of liver sinusoidal endothelial cells. Cancer Lett 2009; 284 (2): 216-221.

14. Watanabe $\mathrm{N}$, Ikeda $\mathrm{H}$, Nakamura $\mathrm{K}$ , Ohkawa R, Kume Y, Aoki J, Hama K, et al. Both plasma lysophosphatidic acid and serum autotaxin levels are increased in chronic hepatitis C.J ClinGastroenterol 2007; 41(6): 616-623.

15. Pleli T, Martin D, Kronenberger B, Brunner F, Köberle V, Grammatikos G, Farnik H, et al. Serum autotaxin is a parameter for the severity of liver cirrhosis and overall survival in patients with liver cirrhosis--a prospective cohort study. PLoS One 2014; 9(7): e103532.

16. Nustad K, Paus E, Kierulf B andBørmer OP.Specificity and affinity of 30 monoclonal antibodies against alphafetoprotein.TumourBiol 1998;19(4):293300.

17. Butler JE, Spradling JE, Suter M, Dierks SE, Heyermann H, Peterman JH.The immunochemistry of sandwich ELISAs--I. The binding characteristics of immunoglobulins to monoclonal and polyclonal capture antibodies adsorbed on plastic and their detection by symmetrical 
and asymmetrical antibody-enzyme conjugates. Molecular immunology 1986; 23(9): 971-82.

18. Wai CT, Greenson JK, Fontana RJ,Kalbfleisch JD, Marrero JA, Conjeevaram HS, Lok AS. A simple noninvasive index can predict both significant fibrosis and cirrhosis in patients with chronic HCV. Hepatology 2003; 38(2): 518-526.

19. Poynard $T$ and Bedossa P. Age and platelet count: a simple index for predicting the presence of histological lesions in patients with antibodies to hepatitis $\mathrm{C}$ virus. METAVIR and CLINIVIR Cooperative Study Groups. J Viral Hepat 1997; 4(3):199-208.

20. Bedossa $P$ and Poynard T.An algorithm for the grading of activity in chronic hepatitis C. for the METAVIR Cooperative Study Group.Hepatology 1996; 24: 289-293.

21. Perrakis A and Moolenaar WH. Autotaxin: structure-function and signaling. J Lipid Res 2014; 55(6): 10101018.

22. Benesch MG, Ko YM, McMullen TPand Brindley DN.Autotaxin in the crosshairs: taking aim at cancer and other inflammatory conditions. FEBS Lett 2014; 588(16): 2712-2727.

23. Nakagawa $H$, Ikeda $H$, Nakamura K, Ohkawa R, Masuzaki R, Tateishi $\mathrm{R}$, Yoshida $\mathrm{H}$, et al. Autotaxin as a novel serum marker of liver fibrosis. Clinica ChimicaActa 2011; 412(13-14):12011206.

24. Rockey DC, Boyles JK, Gabbiani G and Friedman SL. Rat hepatic lipocytes express smooth muscle actin upon activetion in vivo and in culture. $J$ Submicrosc CytolPathol 1992; 24(2):193-203.

25. Yamaoka K, Nouchi $T$, Marumo $F$ and Satoc C. Alpha-smooth-muscle actin expression in normal and fibrotic human livers. Dig Dis Sci1993; 38(8): 14731479.
26. Tanaka M, Okudaira S, Kishi Y, Ohkawa R, Iseki S, Ota M, Noji S, et al.Autotaxin stabilizes blood vessels and is required for embryonic vasculature by producing lysophosphatidic acid. J BiolChem2006; 281(35):25822-25830.

27. Garc1 'a-Paga'nJC, Gracia-SanchoJ and BoschJ. Functional aspects on the pathophysiology of portal hypertension in cirrhosis.J Hepatol 2012; 57(2):458-461.

28. Ezzat WM,Ragab HM, El MaksoudNA, Abdulla NA, Yasser A and Elhosary YA. Validity of Autotaxin as a Novel Diagnostic Marker for Liver Fibrosis in Egyptian Chronic HCV Patients. Maced J Med Sci2013; 6(4): 359-364.

29. Fouad SA, Esmat S, Omran D, Rashid L and Kobaisi MH. Non-invasive assessment of hepatic fibrosis in Egyptian patients with chronic hepatitis $\mathrm{C}$ virus infection. World J Gastroenterology 2012; 18(23): 2988-2994.

30. Attallah AM, El-Far M, Omran MM, Farid K, Albannan MS and El-Dosoky I. Noninvasive Diagnosis of Liver Fibrosis and Cirrhosis in Chronic Hepatitis C Patients. Journal of clinical laboratory analysis 2013; 27(2): 121-129.

31. Lackner C, Struber G, Liegl B, Leibl S, Ofner P, Bankuti C, Bauer B, et al. Comparison and validation of simple noninvasive tests for prediction of fibrosis in chronic hepatitis C. Hepatology 2005; 41(6):1376-1382.

32. Cadranel JF and Philippe M.Prothrombin index decrease: a useful and reliable marker of extensive fibrosis. Eur $J$ Gastroenterol Hepatol 2002; 14(10): 1057-1059.

33. Mistry PK and Jain D.Haematological disorders of the liver. In: Dooley JS, Lok ASF, Burroughs AK and Heathcote EJ(eds.).Sherlock's Diseases of The Liver and Biliary System. 12th ed. United Kingdom: Blackwell Publishing Ltd, 2011, p. 48-69. 
34. Coverdale SA, Samarasinghe DA, Lin R, Kench J, Byth K, Khan MH, Crewe E, et al. Changes in antipyrine clearance and platelet count, but not conventional liver tests, correlate with fibrotic change in chronic hepatitis $\mathrm{C}$ : value for predicting fibrotic progression. Am. J. Gastroenterol 2003; 98(6): 1384-1390.

35. Friedman SL, Mantin $\mathrm{P}$ and Munoz SJ. Laboratory methods for evalution of the patients with liver disease. In: Zakim D, Boyer TD(eds.).A textbook of liver diseases. Philadelphia: saunder, 2002, p. 661-708.

36. Elias E. Jaundice and cholestasis. In: Dooley JS, Lok ASF, Burroughs AK and Heathcote EJ (eds.).Sherlock's Diseases of The Liver and Biliary System.12th ed. Blackwell Publishing Ltd, 2011, p.234256.

37. Omran MM, Farid K, Emran TM and Attallah AA. Fibro $\alpha$-score as a simple and useful non-invasive test for predicting significant liver fibrosis in chronic hepatitis C patients. Arab Journal of Gastroenterology 2011; 12(2):74-79.

38. Taketa K. Alpha fetoprotein: reevaluation in hepatology. Hepatology 1990; 12(6): 1420-1432.

39. Adinolfi LE, Utili R, Andreana A, Tripodi MF, Marracino M, Gambardella M, Giordano M, et al. Serum HCV RNA levels correlate with histological liver damage and concur with steatosis in progression of chronic hepatitis C. Dig Dis Sci. 2001; 46(8): 1677-1683.

40. Magrin S, Craxi A, Fabiano C, Simonetti RG, Fiorentino G, Marino L, Diquattro O, et al.Hepatitis $\mathrm{C}$ viremia in chronic liver disease: relationship to interferon-alpha or corticosteroid treatment. Hepatology 1994; 19(2): 273-279.
41. Nousbaum, JB, Pol S, Nalpas B, Landais $\mathrm{P}$, Berthelot $\mathrm{P}$ and Bréchot C. Hepatitis-Cvirus-type $1 \mathrm{~b}$ (II) infection in France and Italy. Collaborative Study Group.Ann. intern. Med 1995; 122(3): 161-168.

42. Shahid M, Idrees M, Nasir B, Raja AJ, Raza SM, Amin I, Rasul A, et al. Correlation of biochemical markers and HCV RNA titers with fibrosis stages and grades in chronic HCV-3a patients. Eur $J$ Gastroenterol Hepatol 2014; 26(7): 788794. 